\title{
Análise das expressões da largura da diagonal equivalente para a modelagem de pórticos preenchidos com alvenaria participante
}

\author{
Analysis of the equivalent strut width expressions \\ for modeling masonry infilled frames
}

Luiz Flávio de Queiroz ${ }^{1}$, Gerson Moacyr Sisniegas Alva ${ }^{1}$

\footnotetext{
${ }^{1}$ Programa de Pós-Graduação em Engenharia Civil, Faculdade de Engenharia Civil, Universidade Federal de Uberlândia, Av. João Naves de Ávila, n. 2121, bloco 1Y, Campus Santa Mônica, CEP 38400-902, Uberlândia, MG, Brasil. e-mail:1zfoqz@gmail.com, alva_gerson@yahoo.com.br
}

\section{RESUMO}

O foco deste trabalho consiste na avaliação dos efeitos da consideração das alvenarias de preenchimento como elemento resistente em estruturas aporticadas de concreto. Nas análises deste trabalho foram incluídas as recomendações da recém atualizada norma brasileira para projeto de alvenaria estrutural - ABNT NBR 16868-1. Expressões presentes na literatura e na norma brasileira foram empregadas para determinar a largura da diagonal equivalente. Modelos bidimensionais com o auxílio do método dos elementos finitos (MEF) foram utilizados para determinação da largura da diagonal equivalente, permitindo comparação com as expressões analíticas da literatura. As diferenças também foram analisadas em termos de deslocamentos horizontais em edifício de concreto armado de múltiplos andares com alvenaria de blocos de concreto. As simulações foram realizadas utilizando os programas ANSYS e FTOOL. O estudo evidenciou grandes diferenças entre os valores das larguras da diagonal equivalente fornecidas pelas expressões da literatura, em todos os quadros isolados (pórticos de um andar). Tais diferenças tiveram influência nos deslocamentos horizontais dos quadros isolados e do edifício. Notou-se que, para os casos analisados, a expressão que mais se aproximou dos resultados obtidos com as simulações via MEF foi a expressão de Mainstone.

Palavras-chave: Alvenaria participante. Análise estrutural. Pórticos preenchidos.

\begin{abstract}
The focus of this paper is to evaluate the effects of considering masonry infill walls as resistant elements in concrete structures. Recommendations of the recently updated Brazilian code for the design of structural masonry - ABNT NBR 16868-1 - were included in the analysis of this paper. Expressions presented in the literature and in Brazilian code were used to determine the equivalent diagonal width. Two-dimensional models with the aid of the Finite Element Method (FEM) were used to determine the equivalent diagonal width allowing the comparison with analytical expressions from the literature. The differences were also analyzed in terms of lateral displacements of a multistory reinforced concrete building with concrete masonry infill walls. The simulations were carried out using ANSYS and FTOOL programs. Significant differences between the values of the equivalent diagonal width obtained by the expressions from the literature were observed in all the single-story single-bay frames. Such differences had influence on the lateral displacements of the singlestory frames and the multistory building. For the cases analyzed, the expression proposed by Mainstone was the one that led to the best results in comparison to MEF simulations.
\end{abstract}

Keywords: Participating masonry. Structural analysis. Infill frames. 


\section{INTRODUÇÃO}

A consideração da alvenaria de preenchimento como elemento resistente é uma solução no auxílio ao contraventamento frente às ações horizontais (sismos e vento) em estruturas aporticadas de edifícios. Assim, além de cumprir a função de vedação (atendendo a requisitos de estanqueidade, isolamento térmico e acústico, estabilidade mecânica, segurança ao fogo, estética, durabilidade e economia) a alvenaria contribui também no suporte de ações.

No entanto, há incertezas quanto à real capacidade resistente das alvenarias, pois esta depende da correta dosagem dos materiais e minuciosa execução, inclusive no que se refere à fixação da interface pórtico/alvenaria. Além disso, a maioria das edificações passa por reformas ao longo de sua vida útil, o que alteraria a capacidade de suporte da estrutura. Em contrapartida vários estudos presentes na literatura demonstram que a presença da alvenaria promove aumento da rigidez dos sistemas estruturais em pórticos e que a mesma interfere na redistribuição de esforços entre os elementos estruturais.

Os estudos sobre o tema, em cenário internacional, apresentam simulações experimentais e numéricas, motivados em especial pela necessidade de combater os efeitos das ações sísmicas. No Brasil, a recém atualizada norma de projeto de alvenaria estrutural - ABNT NBR 16868-1 [1] incluiu um anexo informativo para a consideração da participação da alvenaria. De fato, nas duas últimas décadas no Brasil os estudos sobre o tema têm se intensificado, principalmente no sentido de considerar a alvenaria como elemento resistente às ações horizontais, em especial a força do vento. $\mathrm{O}$ modelo da diagonal equivalente é o mais utilizado, atualmente, para simulação do comportamento da alvenaria associada ao pórtico. Neste modelo uma barra birrotulada é inserida na diagonal comprimida e tem suas propriedades físicas e mecânicas definidas de acordo com a parede que a barra representa. No entanto a definição da largura da diagonal gera discussões, pois as expressões presentes na literatura fornecem resultados muito diferentes entre si.

Ensaios experimentais foram realizados ao longo dos anos para determinar o comportamento de pórticos preenchidos. No entanto estes nem sempre são viáveis, uma vez que demandam investimentos financeiros e de tempo. Por sua vez, o desenvolvimento de modelos numéricos capazes de representar o comportamento real das estruturas é de grande importância no caso de pórticos preenchidos com alvenarias. Nesta busca, atenção especial é dispensada à interface de contato entre os dois elementos (pórtico e parede de alvenaria), pois é necessária simulação do contato e deslizamento entre eles.

O objetivo central do trabalho é comparar a largura da diagonal equivalente fornecida pelas expressões analíticas encontradas na literatura, entre si (Modelo de Diagonal Equivalente - MDE), e com os resultados fornecidos a partir das simulações numéricas via Método dos Elementos Finitos (MEF), com a utilização do programa ANSYS. Para alcançar o objetivo central, foram simulados pórticos de concreto armado preenchidos com alvenaria de blocos estruturais de concreto (alvenaria participante) submetidos a ações horizontais de Estado Limite Último. Nesse contexto procura-se verificar qual expressão representa mais fielmente os pórticos analisados e a influência exercida pela largura da diagonal equivalente nos deslocamentos horizontais.

\section{PESQUISAS PRÉVIAS: MODELO DA DIAGONAL EQUIVALENTE}

Alvenaria participante é a alvenaria estrutural construída dentro de um pórtico intencionalmente dimensionada e construída como parte do sistema de contraventamento [1]. O papel da alvenaria é determinado de acordo com a concepção estrutural e a fixação ao pórtico de concreto.

No entanto, o uso da alvenaria em Estado Limite Último evoluiu a partir de outros estudos, que visavam determinar qual o papel desenvolvido pela alvenaria de preenchimento na rigidez lateral da edificação. Os estudos sobre o assunto têm o marco inicial em fortes rajadas de vento no Edifício Empire State, nos EUA, onde só foram notadas deformações no pórtico de aço após surgimento de fissuras em algumas alvenarias, evidenciando-se o papel resistente exercido pelas mesmas [2].

As inúmeras pesquisas internacionais realizadas sobre o assunto foram fortemente influenciadas pela ação dos sismos, que elevam a ação das forças horizontais nas edificações. POLYAKOV [3] estudou a resistência à tração e ao cisalhamento de alvenarias de preenchimento, caracterizando os estágios de comportamento caracterizou de pórticos preenchidos quando submetidos a elevadas forças laterais. Atribui-se a POLYAKOV [3] a introdução do conceito de diagonal equivalente. A modelagem consiste em simular a parede por meio de uma barra birrotulada definida nos pontos de encontro viga-pilar, sendo a espessura e o módulo de elasticidade os mesmos da alvenaria.

PARSEKIAN, HAMID e DRYSDALE [4] descrevem o comportamento dos pórticos preenchidos segundo os diferentes estágios de carregamento horizontal. No primeiro estágio existe contato total entre pórti- 
co e alvenaria, pois a ação horizontal é pequena (Figura 1a). No segundo estágio, devido ao aumento da força, ocorre a separação entre pórtico e parede (Figura 1b). Esse é o estágio que caracteriza o comportamento da parede como uma barra diagonal comprimida. Com o aumento do carregamento, começam a aparecer fissuras no pórtico e/ou na parede, até que a alvenaria atinja a ruptura por cisalhamento, por tração diagonal ou por compressão diagonal (Figura 1c, 1d e 1e) ou até que ocorra a ruptura da seção dos pilares (Figura 1f).

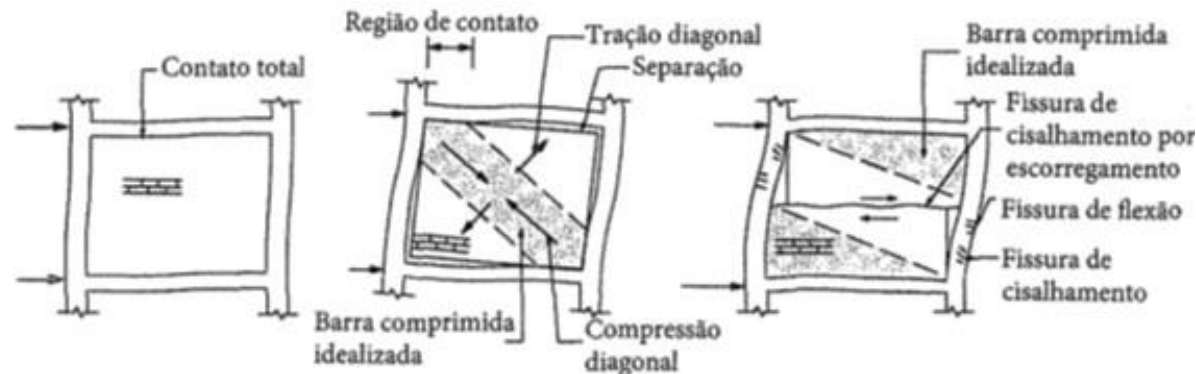

(a) Total açào conjunta

(b) Diagonal comprimida

(c) Dupla diagonal comprimida

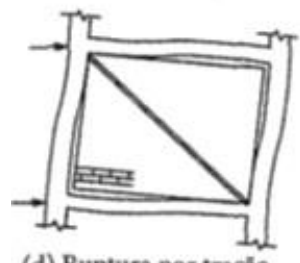

(d) Ruptura por traçăo diagonal

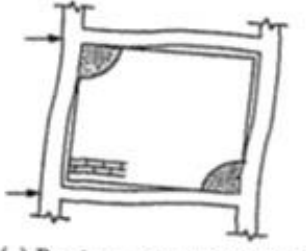

(e) Ruptura por esmagamento dos cantos

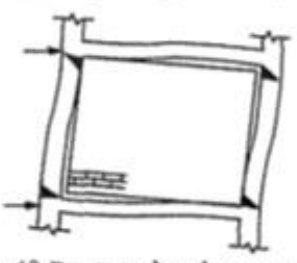

(f) Ruptura dos elementos do portico

Figura 1: Deformações e modos de ruptura de pórticos preenchidos com alvenaria [4].

CRISAFULLI e CARR [5] propuseram a modelagem da parede com duas diagonais. O modelo considera separadamente a compressão e o cisalhamento da alvenaria por meio de uma treliça dupla e uma mola de cisalhamento, respectivamente, em cada direção. Afirmam que dessa forma é feita uma adequada consideração da rigidez lateral da resistência na alvenaria. Os autores mostram que o modelo é de fácil aplicação para grandes estruturas, no entanto é limitado por sua simplicidade, não sendo capaz de prever adequadamente o momento fletor e as forças de cisalhamento no pórtico que envolve a alvenaria. A modelagem foi comparada com resultados experimentais e juntamente com outras, presentes na literatura, concluiu-se que o modelo é capaz de representar o comportamento de quadros preenchidos desde que haja uma fina calibração, em especial dos parâmetros que definem o comportamento histerético da alvenaria.

CHRYSOSTOMOU e ASTERIS [6] estudaram a contribuição da alvenaria na resistência das estruturas frente a ações sísmicas. Apresentaram equações para quantificar a rigidez no plano da alvenaria, a resistência e a capacidade de deformação das paredes, bem como métodos simplificados para prever a forma de ruptura. Concluindo seus estudos, apresentam recomendações quanto às propriedades dos materiais, modos de ruptura, resistência e rigidez dos pórticos preenchidos, além de características das deformações desse tipo de estrutura.

No Brasil, as principais contribuições de pesquisa sobre o tema iniciaram-se há duas décadas. Dentre as que abordaram a modelagem com diagonais equivalentes, podem ser citadas das contribuições de ALV ARENGA [2], SANTOS [7], MADIA [8], SILVA [9], SOUSA [10], ALVA et al. [11], MONTANDON [12], MEDEIROS [13], GRANDI [14], ALVA e MONTANDON [15] e QUEIROZ [16].

Quanto a largura da diagonal equivalente, embora existam várias expressões presentes na literatura para sua determinação, as mesmas fornecem valores muito diferentes entre si. Percebe-se, porém que, para todas as formulações a largura da diagonal equivalente depende da relação entre as propriedades mecânicas e geométricas da alvenaria e do pórtico. Na Tabela 1 estão resumidas as principais expressões aplicáveis à modelagem com uma diagonal equivalente, a qual é empregada neste trabalho. 
Tabela 1: Largura da diagonal equivalente.

\begin{tabular}{|c|c|}
\hline AUTORES & EXPRESSÕES ANALÍTICAS \\
\hline MAINSTONE [17] & $w=0,175 \cdot\left(\lambda_{H}\right)^{-0,4} \cdot D$ \\
\hline HENDRY [18] & $w=\frac{\sqrt{\alpha_{p}^{2}+\alpha_{v}^{2}}}{2} \quad \alpha_{v}=\frac{\pi}{\lambda_{v}} \leq l \quad \alpha_{p}=\frac{\pi}{2 \cdot \lambda_{l}}$ \\
\hline LIAUW e KWAN [19] & $w=\frac{0,95 \cdot \operatorname{sen}(2 \theta)}{2 \cdot \sqrt{\lambda_{H}}} \cdot D$ \\
\hline $\begin{array}{l}\text { DECANINI e FANTIN [20]: } \\
\text { NÃO FISSURADO-1 }\end{array}$ & $\begin{array}{cc}\lambda_{H} \leq 7,85 & \lambda_{H}>7,85 \\
w=\left(0,085+\frac{0,748}{\lambda_{H}}\right) \cdot D & w=\left(0,130+\frac{0,393}{\lambda_{H}}\right) \cdot D\end{array}$ \\
\hline $\begin{array}{l}\text { DECANINI e FANTIN [20]: } \\
\text { FISSURADO-2 }\end{array}$ & $\begin{array}{cc}\lambda_{H} \leq 7,85 & \lambda_{H}>7,85 \\
w=\left(0,010+\frac{0,707}{\lambda_{H}}\right) \cdot D & w=\left(0,040+\frac{0,470}{\lambda_{H}}\right) \cdot D\end{array}$ \\
\hline $\begin{array}{l}\text { PAULAY e PRIESTLEY } \\
\text { [21] }\end{array}$ & $w=\frac{D}{4}$ \\
\hline DURRANI e LUO [22] & $\begin{array}{c}w=\gamma \cdot \operatorname{sen}(2 \theta) \cdot D \\
\gamma=0,32 \sqrt{\operatorname{sen}(2 \theta)} \cdot\left(\frac{H^{4} \cdot E \cdot t}{m \cdot E_{p} \cdot I_{p} \cdot h}\right)^{-0,1} \\
m=6 \cdot\left(\frac{1+6 \cdot E_{v} \cdot I_{v} \cdot H}{\pi \cdot E_{P} \cdot I_{P} \cdot L}\right)\end{array}$ \\
\hline $\begin{array}{l}\text { CHRYSOSTOMOU e } \\
\text { ASTERIS [6] }\end{array}$ & $w=0,27 \cdot\left(\lambda_{H}\right)^{-0,4} \cdot D$ \\
\hline $\begin{array}{l}\text { CSA S304 [23] } \\
\text { ABNT NBR 16868-1 [1] }\end{array}$ & $w=$ menor valor entre HENDRY [18] e D/4 \\
\hline$\lambda_{H}=\lambda_{p} \cdot H$ & $\lambda_{p}=\sqrt{\frac{E \cdot t \cdot \operatorname{sen}(2 \theta)}{4 \cdot E_{p} \cdot I_{p} \cdot h}}$ \\
\hline
\end{tabular}

Na Tabela 1:

$\mathrm{w}$ - largura da diagonal equivalente

$\alpha_{\mathrm{p}}$ - comprimento de contato entre a parede e o pilar

$\alpha_{\mathrm{v}}$ - comprimento de contato entre a parede e a viga

D - comprimento da diagonal da parede

E - Módulo de elasticidade do material da parede

$\mathrm{E}_{\mathrm{p}}$ - Módulo de elasticidade do pilar

$\mathrm{E}_{\mathrm{v}}$ - Módulo de elasticidade da viga

$\mathrm{h}$ - altura da parede 
$\mathrm{h}_{\mathrm{p}}$ - altura da seção transversal do pilar

$\mathrm{h}_{\mathrm{v}}$ - altura da seção transversal da viga

$\mathrm{I}_{\mathrm{p}}$ - Momento de inércia do pilar no plano do pórtico em torno do eixo de flexão

$\mathrm{I}_{\mathrm{v}}$ - Momento de inércia da viga no plano do pórtico em torno do eixo de flexão

$\mathrm{H}$ - Distância entre eixos de vigas (distância entre andares)

1 - Comprimento da parede

L - Distância entre eixos de pilares (vão teórico da viga)

$\theta$ - Ângulo da diagonal equivalente em relação à horizontal

$\mathrm{t}$ - espessura da parede

A ABNT NBR 16868-1[1] emprega a mesma expressão da norma canadense CSA S304 [23] para a largura da diagonal equivalente, sendo t igual à duas vezes a soma da espessura das paredes longitudinais do bloco para o caso de bloco vazado não totalmente grauteado. Para o caso de tijolo maciço ou bloco vazado totalmente grauteado, t é própria a espessura da parede.

SILVA [14] analisou pórticos preenchidos com alvenaria de vedação com intensidade de ações horizontais associados a Estado Limite de Serviço, a fim de verificar a contribuição do painel na rigidez global e avaliar os efeitos dos esforços horizontais sobre a parede. A autora observou variação de mais de $200 \%$ entre as expressões analíticas que determinam a largura da diagonal equivalente para painéis que não possuem aberturas. Concluiu que as formulações que apresentam melhores resultados são as de LIAUW e KWAN [19], DURRANI e LUO [22] e CHRYSOSTOMOU e ASTERIS [6] e que, apesar de ser a mais utilizada, a expressão de MAINSTONE [17] é a que apresenta resultados mais conservadores.

A partir de simulações de modelos MDE e MEF para painéis de concreto armado preenchidos com alvenaria de bloco cerâmico, MONTANDON [12] confirmou a grande discrepância entre os valores de diagonal equivalente obtidos com o uso das diferentes expressões analíticas encontradas na literatura, sendo que a formulação de DURRANI e LUO [22] foi a que mais se aproximou dos resultados obtidos por meio da modelagem via MEF. Por fim, o autor propôs também uma nova formulação para o cálculo da largura da diagonal, a partir de alterações na expressão de MAINSTONE [17].

Por fim, QUEIROZ [16] deu continuidade às investigações de MONTANDON [12], analisando, entretanto, alvenarias com propriedades mecânicas de blocos estruturais de concreto e utilizando as recomendações do projeto de norma da NBR 16868, que estava em fase de aprovação na época.

\section{MATERIAIS E MÉTODOS}

\subsection{Determinação da largura da diagonal equivalente: pórticos de um único andar}

A comparação da largura da diagonal equivalente para pórticos de um andar com alvenaria participante de blocos de concreto em Estado Limite Último foi realizada com duas modelagens: modelos via MEF, a partir da aplicação do programa computacional ANSYS (R18 plataforma Mechanical APDL) e modelos MDE, por meio do programa FTOOL para a resolução de pórticos planos, conforme ilustrado nas Figuras 2 e 3 .

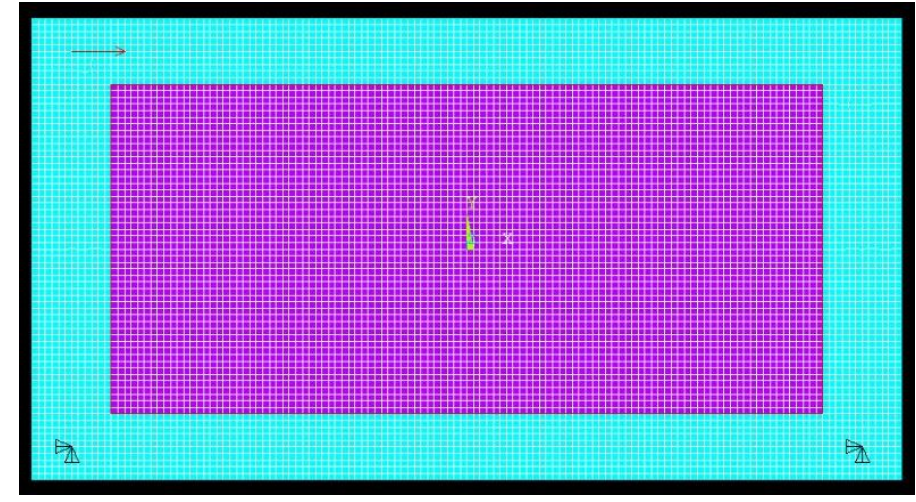

Figura 2: Modelo MEF (ANSYS). 


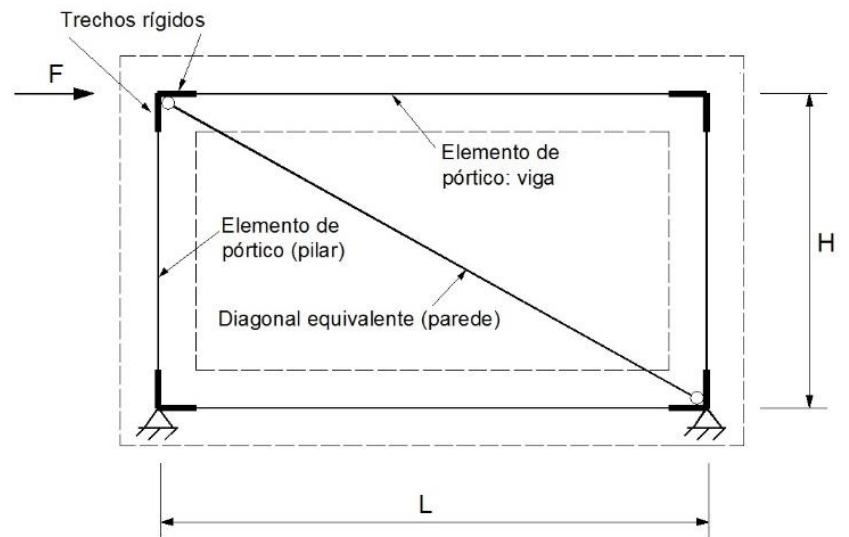

Figura 3: Modelos utilizados na determinação da largura da diagonal equivalente.

Os modelos apresentados neste trabalho foram adaptações de modelos simulados por MONTANDON [12], considerando os pilares do pórtico de mesma seção transversal, e que fizeram parte das investigações de QUEIROZ [16]. Foram utilizados quadros (pórticos) de comprimento L $=4,5 \mathrm{~m}, 6,0 \mathrm{~m}$ e 7,5 m; pé-direito estrutural $\mathrm{H}=3,0 \mathrm{~m}$; vigas de seção transversal $20 \mathrm{~cm} \times 40 \mathrm{~cm}, 20 \mathrm{~cm} \times 50 \mathrm{~cm}$ e $20 \mathrm{~cm} \times 60 \mathrm{~cm}$; e pilares de seção $20 \mathrm{~cm} \times 40 \mathrm{~cm}, 20 \mathrm{~cm} \times 60 \mathrm{~cm}, 20 \mathrm{~cm} \times 80 \mathrm{~cm}$ e $20 \mathrm{~cm} \times 100 \mathrm{~cm}$. A espessura da alvenaria para todas as simulações foi de $20 \mathrm{~cm}$.

Para pilares e vigas foi utilizado concreto armado com $\mathrm{f}_{\mathrm{ck}}$ de $25 \mathrm{MPa}$, módulo de elasticidade igual a $2,5 \times 10^{4} \mathrm{MPa}$ - estimado conforme ABNT NBR 6118 [24] - e coeficiente de Poisson igual a 0,20. A fim de simplificar as análises, o material foi admitido como isotrópico e elástico-linear.

A alvenaria, composta por blocos vazados de concreto, teve suas características mecânicas determinadas conforme prescrições da ABNT NBR 16868-1 [1]. Foram utilizados blocos de resistência característica a compressão de 4,0; 8,0;12,0 e 16,0 MPa. Conforme as prescrições contidas na norma foram determinadas as resistências da argamassa e do prisma, o coeficiente de Poisson de 0,20 e o módulo de elasticidade calculado em função da resistência do prisma: $2,6 \cdot 10^{3} \mathrm{MPa} ; 4,8 \cdot 10^{3} \mathrm{MPa} ; 6,7 \cdot 10^{3} \mathrm{MPa} ; 8,3 \cdot 10^{3}$ (respectivamente para os blocos de $\mathrm{f}_{\mathrm{bk}} 4,0 ; 8,0 ; 12,0$ e 16,0 MPa). A alvenaria também foi admitida como material isotrópico e elástico-linear.

Os parâmetros de resistência ao cisalhamento foram determinados conforme o critério de Coulomb. A norma estabelece os coeficientes da equação em função da resistência da argamassa utilizada em cada caso. Como a análise em elementos finitos fornece a tensão em cada nó (ou em cada elemento finito), é necessário também atentar-se à máxima tensão resistente ao cisalhamento, indicada pela norma. Portanto, de acordo com a norma, o coeficiente de atrito para todas as situações é igual a 0,5 . A coesão e a máxima tensão de cisalhamento para as alvenarias com blocos de resistência à compressão de 4,0 e 8,0 MPa são iguais à 0,150 MPa e 1,4 MPa, respectivamente. Para as alvenarias de blocos com resistência à compressão de 12,0 e 16,0 MPa a coesão e a máxima tensão de cisalhamento igual são iguais a 0,345 MPa e 1,7 MPa, respectivamente.

Quanto à força horizontal aplicada em cada modelo, partiu-se do exposto por MONTANDON [12] na definição do carregamento. No trabalho desenvolvido pelo autor foram aplicadas forças de vento capazes de produzir, na estrutura não preenchida por alvenaria, deslocamentos relativos entre dois andares consecutivos iguais a H/850 (limite recomendado pela ABNT NBR 6118 [24] para verificação dos Estados Limites de Serviço), sendo H a distância entre andares consecutivos. Segundo a ABNT NBR 6118 [24], para a combinação frequente de serviço (ELS), o fator de redução $\psi_{2}$ da ação do vento é igual a 0,3 . Para as combinações do Estado Limite Último (ELU) em que o vento é ação variável principal, o coeficiente de ponderação é igual a 1,4. Desta forma, tem-se uma relação de aproximadamente 4,5 vezes entre os valores das ações do ELU e do ELS. Assim, as forças aplicadas por MONTANDON [12] foram multiplicadas por 4,5 e aplicadas aos novos modelos em análise.

A Tabela 2 apresenta um resumo das principais características dos modelos analisados, incluindo a nomenclatura adotada para cada modelo, para os pórticos de 4,5 m; $6,0 \mathrm{~m}$ e 7,5 m de vão da viga. As variáveis correspondem a: $f_{b k}-$ resistência característica à compressão do bloco; $f_{a}-$ resistência média à compressão da argamassa; $\mathrm{f}_{\mathrm{pk}}$ - resistência característica à compressão do prisma; $\mathrm{E}_{\mathrm{a}}-$ módulo de elasticidade da alvenaria participante. 
Tabela 2: Modelos analisados.

\begin{tabular}{|c|c|c|c|c|c|c|c|}
\hline MODELO & $\mathrm{f}_{\mathrm{bk}}(\mathrm{MPa})$ & $\mathrm{f}_{\mathrm{a}}(\mathrm{MPa})$ & $f_{p k}(M P a)$ & $\mathrm{E}_{\mathrm{a}}(\mathrm{MPa})$ & $\underset{(\mathrm{MPa})}{\mathrm{COESÃO}}$ & $\begin{array}{c}\text { DIMENSÕES DO } \\
\text { PILAR (cm) }\end{array}$ & $\begin{array}{l}\text { FORÇA APLI- } \\
\text { CADA (kN) }\end{array}$ \\
\hline \multicolumn{8}{|c|}{$\mathrm{L}=4,5 \mathrm{~m}($ Viga $20 \mathrm{~cm} \times 40 \mathrm{~cm})$} \\
\hline B4V40P40 & 4,0 & 4,0 & 3,2 & $2,6 \times 10^{3}$ & 0,150 & $20 \times 40$ & 162,90 \\
\hline B4V40P60 & 4,0 & 4,0 & 3,2 & $2,6 \times 10^{3}$ & 0,150 & $20 \times 60$ & 238,50 \\
\hline B4V40P80 & 4,0 & 4,0 & 3,2 & $2,6 \times 10^{3}$ & 0,150 & $20 \times 80$ & 292,95 \\
\hline B4V40P100 & 4,0 & 4,0 & 3,2 & $2,6 \times 10^{3}$ & 0,150 & $20 \times 100$ & 344,70 \\
\hline B8V40P40 & 8,0 & 6,0 & 6,0 & $4,8 \times 10^{3}$ & 0,150 & $20 \times 40$ & 162,90 \\
\hline B8V40P60 & 8,0 & 6,0 & 6,0 & $4,8 \times 10^{3}$ & 0,150 & $20 \times 60$ & 238,50 \\
\hline B8V40P80 & 8,0 & 6,0 & 6,0 & $4,8 \times 10^{3}$ & 0,150 & $20 \times 80$ & 292,95 \\
\hline B8V40P100 & 8,0 & 6,0 & 6,0 & $4,8 \times 10^{3}$ & 0,150 & $20 \times 100$ & 344,70 \\
\hline $\mathrm{B} 12 \mathrm{~V} 40 \mathrm{P} 40$ & 12,0 & 8,0 & 8,4 & $6,7 \times 10^{3}$ & 0,345 & $20 \times 40$ & 162,90 \\
\hline B12V40P60 & 12,0 & 8,0 & 8,4 & $6,7 \times 10^{3}$ & 0,345 & $20 \times 60$ & 238,50 \\
\hline B12V40P80 & 12,0 & 8,0 & 8,4 & $6,7 \times 10^{3}$ & 0,345 & $20 \times 80$ & 292,95 \\
\hline B12V40P100 & 12,0 & 8,0 & 8,4 & $6,7 \times 10^{3}$ & 0,345 & $20 \times 100$ & 344,70 \\
\hline B16V40P40 & 16,0 & 12,0 & 10,4 & $8,3 \times 10^{3}$ & 0,345 & $20 \times 40$ & 162,90 \\
\hline B16V40P60 & 16,0 & 12,0 & 10,4 & $8,3 \times 10^{3}$ & 0,345 & $20 \times 60$ & 238,50 \\
\hline B16V40P80 & 16,0 & 12,0 & 10,4 & $8,3 \times 10^{3}$ & 0,345 & $20 \times 80$ & 292,95 \\
\hline B16V40P100 & 16,0 & 12,0 & 10,4 & $8,3 \times 10^{3}$ & 0,345 & $20 \times 100$ & 344,70 \\
\hline \multicolumn{8}{|c|}{$\mathrm{L}=6,0 \mathrm{~m}($ Viga $20 \mathrm{~cm} \times 50 \mathrm{~cm})$} \\
\hline B4V50P40 & 4,0 & 4,0 & 3,2 & $2,6 \times 10^{3}$ & 0,150 & $20 \times 40$ & 203,85 \\
\hline B4V50P60 & 4,0 & 4,0 & 3,2 & $2,6 \times 10^{3}$ & 0,150 & $20 \times 60$ & 308,70 \\
\hline B4V50P80 & 4,0 & 4,0 & 3,2 & $2,6 \times 10^{3}$ & 0,150 & $20 \times 80$ & 374,85 \\
\hline B4V50P100 & 4,0 & 4,0 & 3,2 & $2,6 \times 10^{3}$ & 0,150 & $20 \times 100$ & 428,40 \\
\hline B8V50P40 & 8,0 & 6,0 & 6,0 & $4,8 \times 10^{3}$ & 0,150 & $20 \times 40$ & 203,85 \\
\hline B8V50P60 & 8,0 & 6,0 & 6,0 & $4,8 \times 10^{3}$ & 0,150 & $20 \times 60$ & 308,70 \\
\hline B8V50P80 & 8,0 & 6,0 & 6,0 & $4,8 \times 10^{3}$ & 0,150 & $20 \times 80$ & 374,85 \\
\hline B8V50P100 & 8,0 & 6,0 & 6,0 & $4,8 \times 10^{3}$ & 0,150 & $20 \times 100$ & 428,40 \\
\hline B12V50P40 & 12,0 & 8,0 & 8,4 & $6,7 \times 10^{3}$ & 0,345 & $20 \times 40$ & 203,85 \\
\hline B12V50P60 & 12,0 & 8,0 & 8,4 & $6,7 \times 10^{3}$ & 0,345 & $20 \times 60$ & 308,70 \\
\hline B12V50P80 & 12,0 & 8,0 & 8,4 & $6,7 \times 10^{3}$ & 0,345 & $20 \times 80$ & 374,85 \\
\hline B12V50P100 & 12,0 & 8,0 & 8,4 & $6,7 \times 10^{3}$ & 0,345 & $20 \times 100$ & 428,40 \\
\hline B16V50P40 & 16,0 & 12,0 & 10,4 & $8,3 \times 10^{3}$ & 0,345 & $20 \times 40$ & 203,85 \\
\hline B16V50P60 & 16,0 & 12,0 & 10,4 & $8,3 \times 10^{3}$ & 0,345 & $20 \times 60$ & 308,70 \\
\hline B16V50P80 & 16,0 & 12,0 & 10,4 & $8,3 \times 10^{3}$ & 0,345 & $20 \times 80$ & 374,85 \\
\hline B16V50P100 & 16,0 & 12,0 & 10,4 & $8,3 \times 10^{3}$ & 0,345 & $20 \times 100$ & 428,40 \\
\hline
\end{tabular}




\begin{tabular}{|c|c|c|c|c|c|c|c|}
\hline MODELO & $\mathrm{f}_{\mathrm{bk}}(\mathrm{MPa})$ & $\mathrm{f}_{\mathrm{a}}(\mathrm{MPa})$ & $\mathrm{f}_{\mathrm{pk}}(\mathrm{MPa})$ & $\mathrm{E}_{\mathrm{a}}(\mathrm{MPa})$ & $\begin{array}{c}\text { COESÃO } \\
\text { (MPa) }\end{array}$ & \begin{tabular}{|c|} 
DIMENSÕES DO \\
PILAR (cm)
\end{tabular} & $\begin{array}{l}\text { FORÇA APLI- } \\
\text { CADA (kN) }\end{array}$ \\
\hline \multicolumn{8}{|c|}{$\mathrm{L}=7,5 \mathrm{~m}($ Viga $20 \mathrm{~cm} \times 60 \mathrm{~cm})$} \\
\hline B4V60P40 & 4,0 & 4,0 & 3,2 & $2,6 \times 10^{3}$ & 0,150 & $20 \times 40$ & 246,15 \\
\hline B4V60P60 & 4,0 & 4,0 & 3,2 & $2,6 \times 10^{3}$ & 0,150 & $20 \times 60$ & 386,55 \\
\hline B4V60P80 & 4,0 & 4,0 & 3,2 & $2,6 \times 10^{3}$ & 0,150 & $20 \times 80$ & 472,05 \\
\hline B4V60P100 & 4,0 & 4,0 & 3,2 & $2,6 \times 10^{3}$ & 0,150 & $20 \times 100$ & 534,60 \\
\hline B8V60P40 & 8,0 & 6,0 & 6,0 & $4,8 \times 10^{3}$ & 0,150 & $20 \times 40$ & 246,15 \\
\hline B8V60P60 & 8,0 & 6,0 & 6,0 & $4,8 \times 10^{3}$ & 0,150 & $20 \times 60$ & 386,55 \\
\hline B8V60P80 & 8,0 & 6,0 & 6,0 & $4,8 \times 10^{3}$ & 0,150 & $20 \times 80$ & 472,05 \\
\hline B8V60P100 & 8,0 & 6,0 & 6,0 & $4,8 \times 10^{3}$ & 0,150 & $20 \times 100$ & 534,60 \\
\hline B12V60P40 & 12,0 & 8,0 & 8,4 & $6,7 \times 10^{3}$ & 0,345 & $20 \times 40$ & 246,15 \\
\hline B12V60P60 & 12,0 & 8,0 & 8,4 & $6,7 \times 10^{3}$ & 0,345 & $20 \times 60$ & 386,55 \\
\hline B12V60P80 & 12,0 & 8,0 & 8,4 & $6,7 \times 10^{3}$ & 0,345 & $20 \times 80$ & 472,05 \\
\hline B12V60P100 & 12,0 & 8,0 & 8,4 & $6,7 \times 10^{3}$ & 0,345 & $20 \times 100$ & 534,60 \\
\hline B16V60P40 & 16,0 & 12,0 & 10,4 & $8,3 \times 10^{3}$ & 0,345 & $20 \times 40$ & 246,15 \\
\hline B16V60P60 & 16,0 & 12,0 & 10,4 & $8,3 \times 10^{3}$ & 0,345 & $20 \times 60$ & 386,55 \\
\hline B16V60P80 & 16,0 & 12,0 & 10,4 & $8,3 \times 10^{3}$ & 0,345 & $20 \times 80$ & 472,05 \\
\hline B16V60P100 & 16,0 & 12,0 & 10,4 & $8,3 \times 10^{3}$ & 0,345 & $20 \times 100$ & 534,60 \\
\hline
\end{tabular}

Nos modelos MEF com a utilização do programa ANSYS, foram utilizados elementos do tipo PLANE 182, de estado plano de tensões, para a representação do pórtico e do painel de alvenaria. O referido elemento finito possui quatro nós, sendo que cada nó apresenta dois graus de liberdade: as translações no plano da estrutura. Para representar o contato pórtico/alvenaria foram empregados os elementos CONTA172/TARGE169 (determinados pela interface do programa assim que é criado o par de contato), a fim de permitir o deslizamento e a separação entre as superfícies em contato.

Fisicamente os elementos em contato não deveriam admitir nenhuma penetração entre si. No entanto, por problemas de convergência numérica, é necessário permitir certo nível de penetração. O programa ANSYS lida com tal situação a partir de dois coeficientes FKN (fator de rigidez normal de contato) e FTOLN (fator de tolerância à penetração). $\mathrm{O}$ fator FKN dita quanto um corpo é resistente à penetração de outro: quanto maior este fator, menor a penetração. Já o FTOLN é a máxima penetração permitida entre os elementos em contato, calculado como o produto entre a profundidade do elemento e o fator de tolerância à penetração.

A malha nas simulações numéricas foi definida em $5 \mathrm{~cm} \times 5 \mathrm{~cm}$ e conduziu a bons resultados em termos de convergência dos deslocamentos horizontais, da pressão de contato entre pórtico-alvenaria e da redução das penetrações entre as duas superfícies, conforme metodologia também adotada nos trabalhos de SILVA [9] e de MONTANDON [12]. Os fatores FTOLN (0,1 - default do programa) e FKN (maior valor 0,08, sendo necessária diminuição para os pórticos com maior força aplicada a fim de haver convergência numérica) foram calibrados de modo a obter a menor penetração entre os elementos (da ordem de $0,500 \cdot 10^{-3} \mathrm{~m}$ ) garantindo-se a convergência numérica (máximo número de iterações do programa) em todos os casos.

As condições de apoio e a força horizontal foram aplicadas no eixo do encontro pilar/viga, a fim de se aproximar as modelagens (MDE e MEF). Utilizando o critério de igualdade de deslocamentos horizontais com o modelo MEF (programa ANSYS), determinou-se a largura da diagonal equivalente dos modelos MDE (programa FTOOL). Em resumo, foi variada a seção transversal da diagonal equivalente até que o deslocamento horizontal obtido fosse igual ao encontrado na simulação em MEF. Cabe salientar que nos modelos MDE foram considerados os trechos rígidos nos encontros viga/pilar (Figura 3). 


\subsection{Análises de deslocamentos em pórtico de múltiplos andares considerando as expressões da lite- ratura para o cálculo da largura da diagonal equivalente}

O pórtico analisado é apresentado na Figura 4 e contém alvenarias participantes em todos os andares (exceto no primeiro, o térreo). Os dados da estrutura foram extraídos de ALVA et al. [25], com algumas adaptações. Os deslocamentos horizontais e esforços solicitantes foram obtidos com os dois modelos citados no item 3.1: via MEF e com os modelos MDE, sendo nestes últimos a largura da diagonal calculada segundo as mesmas expressões da literatura apresentadas na Tabela 1.

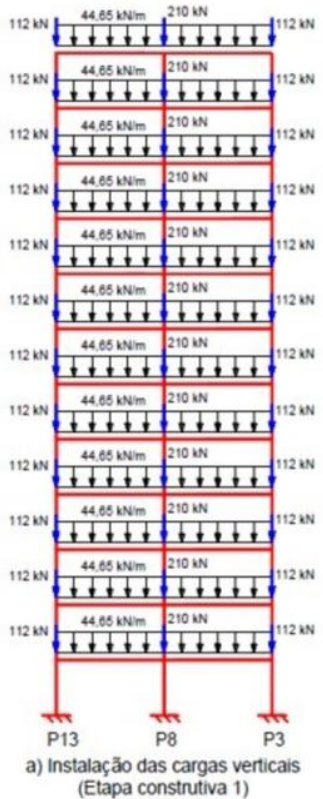

Figura 4: Esquema do pórtico analisado.

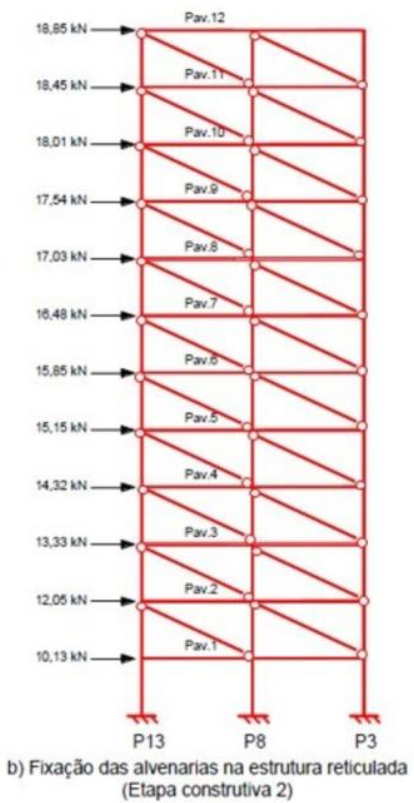

(Etapa construtiva 2)

O vão das vigas é de 6,0 m e o pé direito estrutural, 3,0 m. As forças verticais foram determinadas considerando $25 \mathrm{kN} / \mathrm{m}^{3}$ para o peso específico de concreto armado; paredes em todas as vigas $\left(2,7 \mathrm{kN} / \mathrm{m}^{2} \mathrm{de}\right.$ alvenaria $=14 \mathrm{kN} / \mathrm{m} \times 0,19 \mathrm{~m}) ; 2,0 \mathrm{kN} / \mathrm{m}^{2}$ para a carga variável. Para as forças horizontais da ação do vento, admitiu-se velocidade básica $\mathrm{V}_{0}=31 \mathrm{~m} / \mathrm{s}$ (Belo Horizonte $-\mathrm{MG}$ ); fator topográfico $\mathrm{S}_{1}=1,0$ (terreno plano); terreno categoria IV (terrenos cobertos por obstáculos numerosos e pouco espaçados, com cota média do topo dos obstáculos estimada em $10 \mathrm{~m}$ ); fator estatístico $S_{3}=1,0$ (edificações para hotéis e residências; edificações para comércio com alto fator de ocupação).

A combinação de ações do Estado Limite Último mais crítica para as alvenarias participantes foi aquela em que a ação do vento na fachada de maior dimensão em planta foi considerada como ação variável principal. A fim de estar mais próximo ao que acontece durante a execução de um edifício, foram consideradas duas etapas construtivas: Etapa 1, onde atuam apenas as ações verticais, pois a alvenaria ainda não está fixada à estrutura reticulada de concreto; e Etapa 2, onde atuam as ações horizontais de vento, com as alvenarias já fixadas ao pórtico de concreto.

Ao longo de toda a altura da edificação a partir do primeiro andar, a alvenaria participante possui espessura de $19 \mathrm{~cm}$ e é composta por blocos de concreto com resistência característica à compressão de 10,0 $\mathrm{MPa}$ (módulo de elasticidade igual a 5,6 GPa), com a argamassa de assentamento de resistência média à compressão de 8,0 MPa. As vigas e pilares são constituídos por concreto C25 (módulo de elasticidade igual a 28,0 GPa).

Conforme indicado pela ABNT NBR 16868-1 [1] foram aplicadas as reduções de rigidez na alvenaria participante para a consideração da não-linearidade física (fissuração). Assim, o módulo de elasticidade da alvenaria empregado na análise estrutural foi considerado como $0,5 \mathrm{E}_{\mathrm{a}}$.

O modelo numérico no programa ANSYS foi discretizado conforme as mesmas prescrições aplicadas para os painéis isolados de um só pavimento. Os pilares foram considerados engastados junto às fundações e as forças horizontais aplicadas no eixo do encontro pilar/viga, a fim de se aproximar da modelagem em MDE. 


\section{RESULTADOS E DISCUSSÕES}

\subsection{Determinação da largura da diagonal equivalente: pórticos de um único andar}

Para ilustrar e validar os resultados fornecidos com os modelos MEF, apresentam-se na Figura 5 os diagramas de deformações principais de compressão e de pressão de contato, respectivamente, de um dos pórticos preenchidos analisados (B4V50P60).
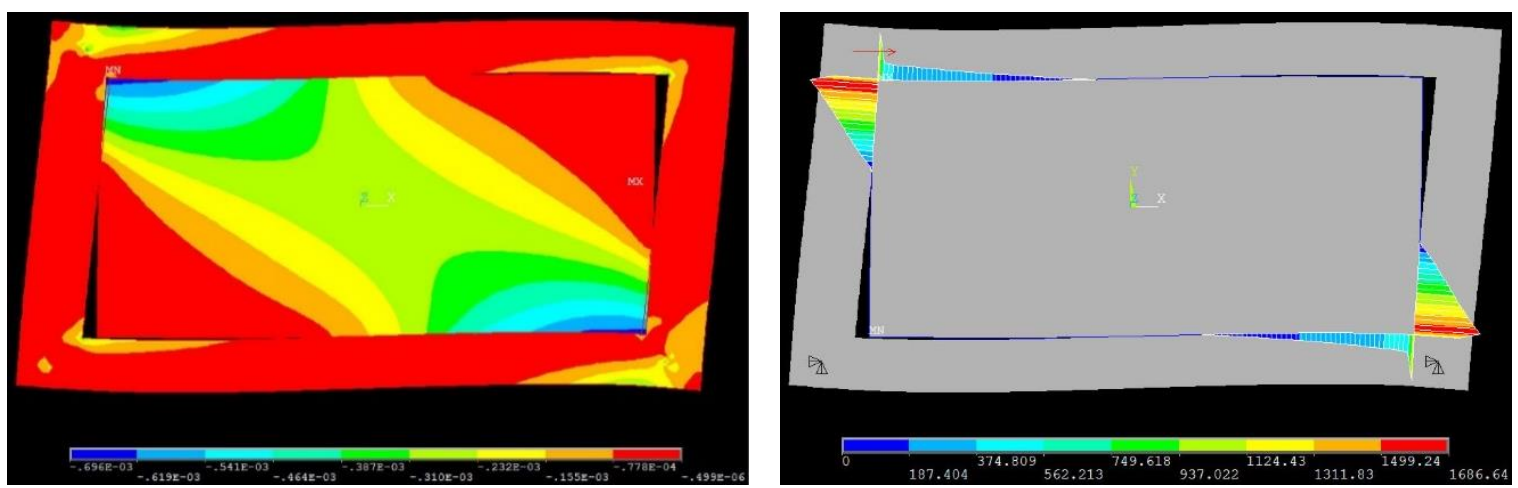

Figura 5: Deformações principais de compressão e pressões de contato $\left(\mathrm{kN} / \mathrm{m}^{2}\right)$

Os valores de deslocamentos horizontais retirados da simulação via MEF foram obtidos no ponto de aplicação da força e utilizados para determinar a largura da diagonal equivalente nos modelos MDE. Os deslocamentos obtidos para cada modelo são apresentados na Tabela 3.

Tabela 3: Deslocamentos horizontais no ponto de aplicação da força

\begin{tabular}{c|c|c|c|c|c}
\hline MODELO & $\begin{array}{c}\text { DESLOCAMENTO } \\
(\mathbf{m m})\end{array}$ & MODELO & $\begin{array}{c}\text { DESLOCAMENTO } \\
(\mathbf{m m})\end{array}$ & MODELO & $\begin{array}{c}\text { DESLOCAMENTO } \\
(\mathbf{m m})\end{array}$ \\
\hline B4V40P40 & 2,66 & B4V50P40 & 3,41 & B4V60P40 & 4,35 \\
\hline B4V40P60 & 3,21 & B4V50P60 & 4,36 & B4V60P60 & 5,60 \\
\hline B4V40P80 & 3,55 & B4V50P80 & 4,76 & B4V60P80 & 6,15 \\
\hline B4V40P100 & 3,76 & B4V50P100 & 4,92 & B4V60P100 & 6,43 \\
\hline B8V40P40 & 1,95 & B8V50P40 & 2,32 & B8V60P40 & 3,21 \\
\hline B8V40P60 & 2,34 & B8V50P60 & 3,16 & B8V60P60 & 3,74 \\
\hline B8V40P80 & 2,65 & B8V50P80 & 3,46 & B8V60P80 & 4,18 \\
\hline B8V40P100 & 2,67 & B8V50P100 & 3,60 & B8V60P100 & 4,43 \\
\hline B12V40P40 & 1,70 & B12V50P40 & 2,11 & B12V60P40 & 2,66 \\
\hline B12V40P60 & 1,99 & B12V50P60 & 2,72 & B12V60P60 & 3,29 \\
\hline B12V40P80 & 2,30 & B12V50P80 & 2,97 & B12V60P80 & 3,59 \\
\hline B12V40P100 & 2,40 & B12V50P100 & 3,09 & B12V60P100 & 3,74 \\
\hline B16V40P40 & 1,65 & B16V50P40 & 2,04 & B16V60P40 & 2,54 \\
\hline B16V40P60 & 1,85 & B16V50P60 & 2,40 & B16V60P60 & 2,95 \\
\hline B16V40P80 & 2,02 & B16V50P80 & 2,63 & B16V60P80 & 3,23 \\
\hline B16V40P100 & 2,14 & B16V50P100 & 2,74 & B16V60P100 & 3,37 \\
\hline
\end{tabular}

Utilizando as expressões descritas na Tabela 1 , também foram calculados os valores de largura da diagonal equivalente. Os resultados estão apresentados nos gráficos das Figuras 6, 7 e 8, juntamente com os obtidos dos resultados da simulação via MEF. Para os modelos analisados, a expressão de HENDRY [18] resul- 
tou, em todos os casos, em valores maiores do que a proposta por PAULAY e PRIESTLEY [21]. Por essa razão, a largura da diagonal equivalente obtida com a ABNT NBR 16868-1 [1] foi limitada pela segunda expressão.
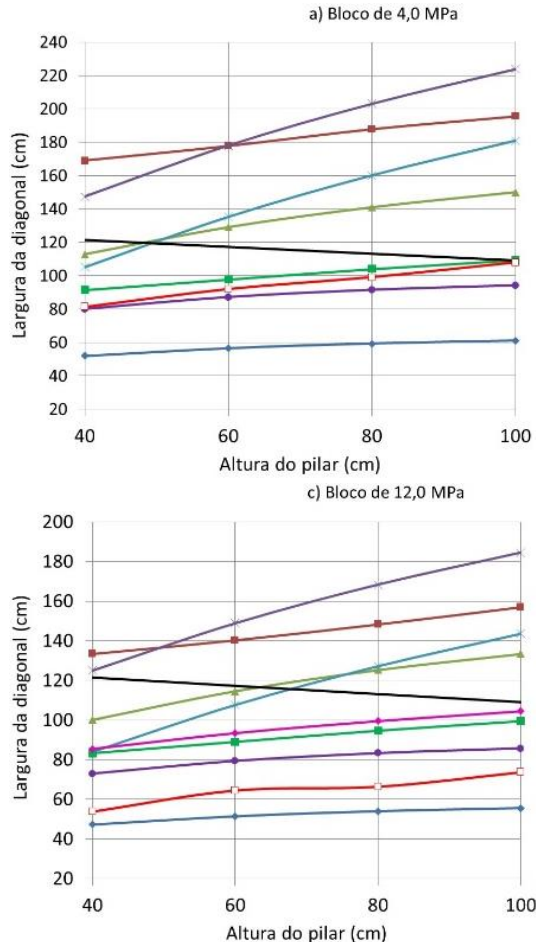

Figura 6: Largura da diagonal equivalente $-\mathrm{L}=4,5 \mathrm{~m}$
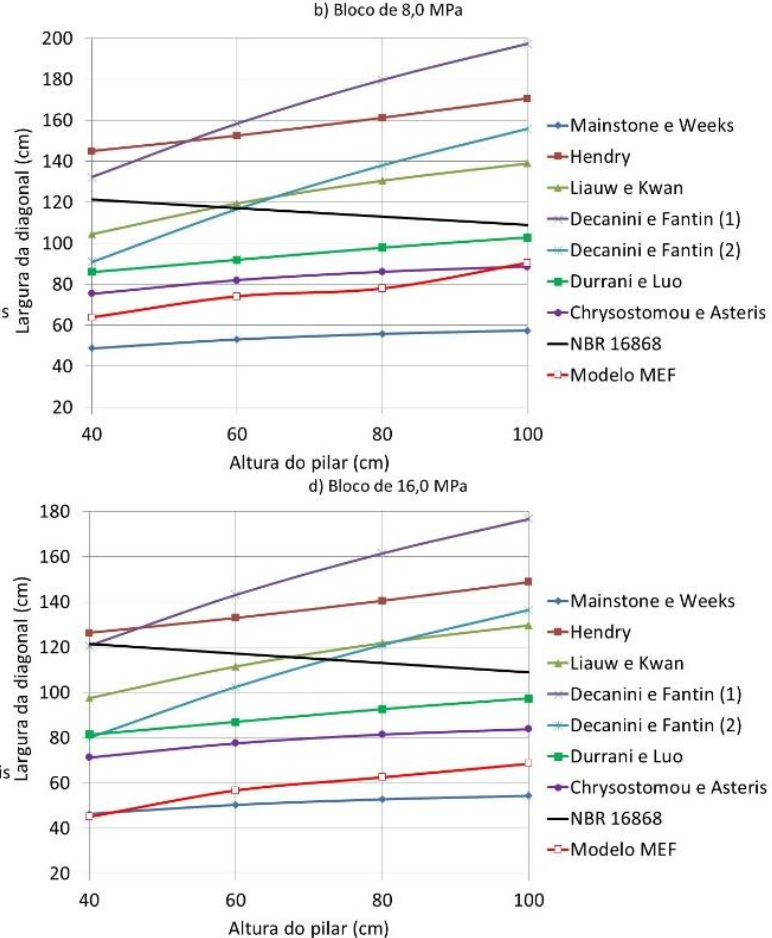
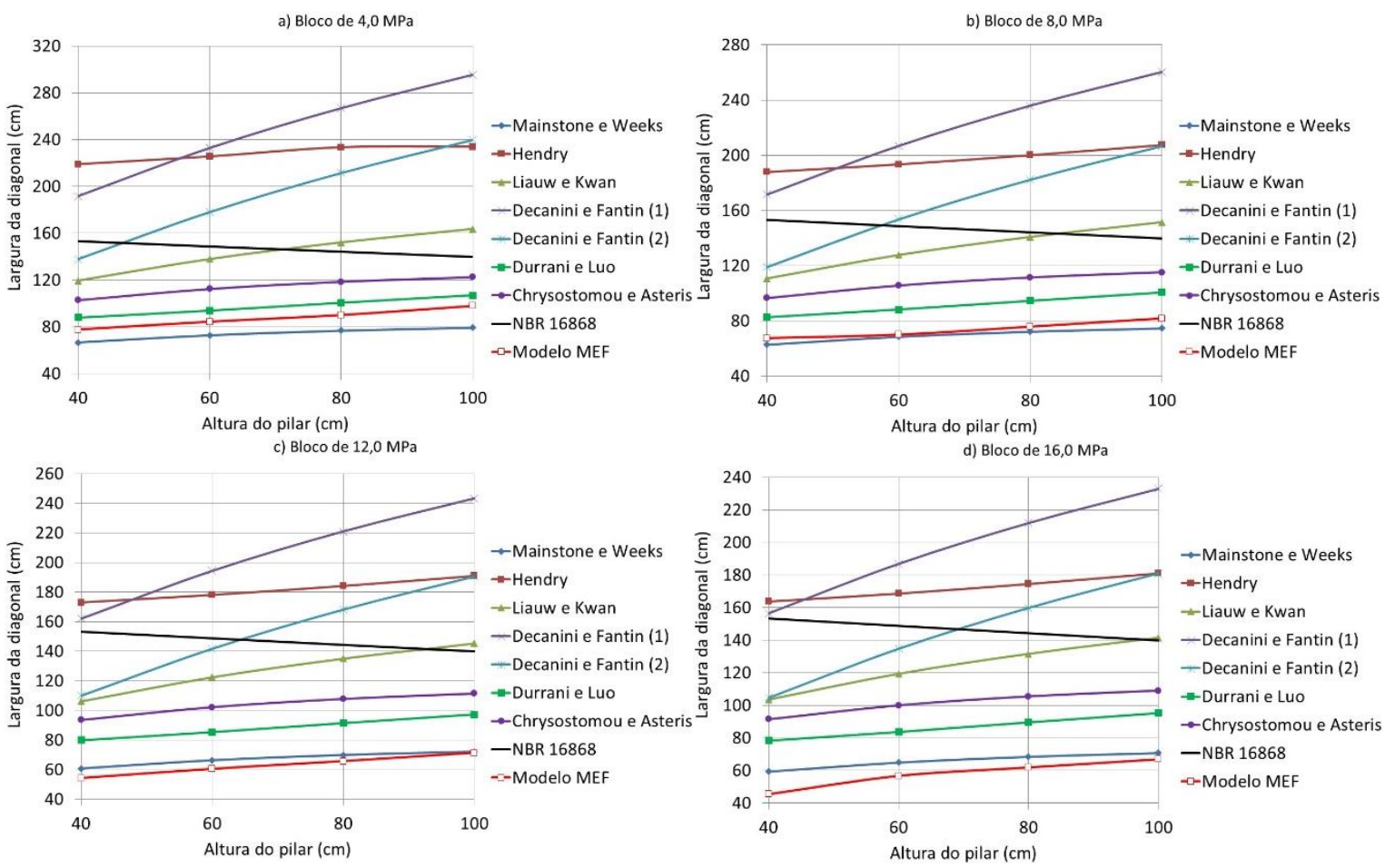

Figura 7: Largura da diagonal equivalente $-\mathrm{L}=6,0 \mathrm{~m}$ 

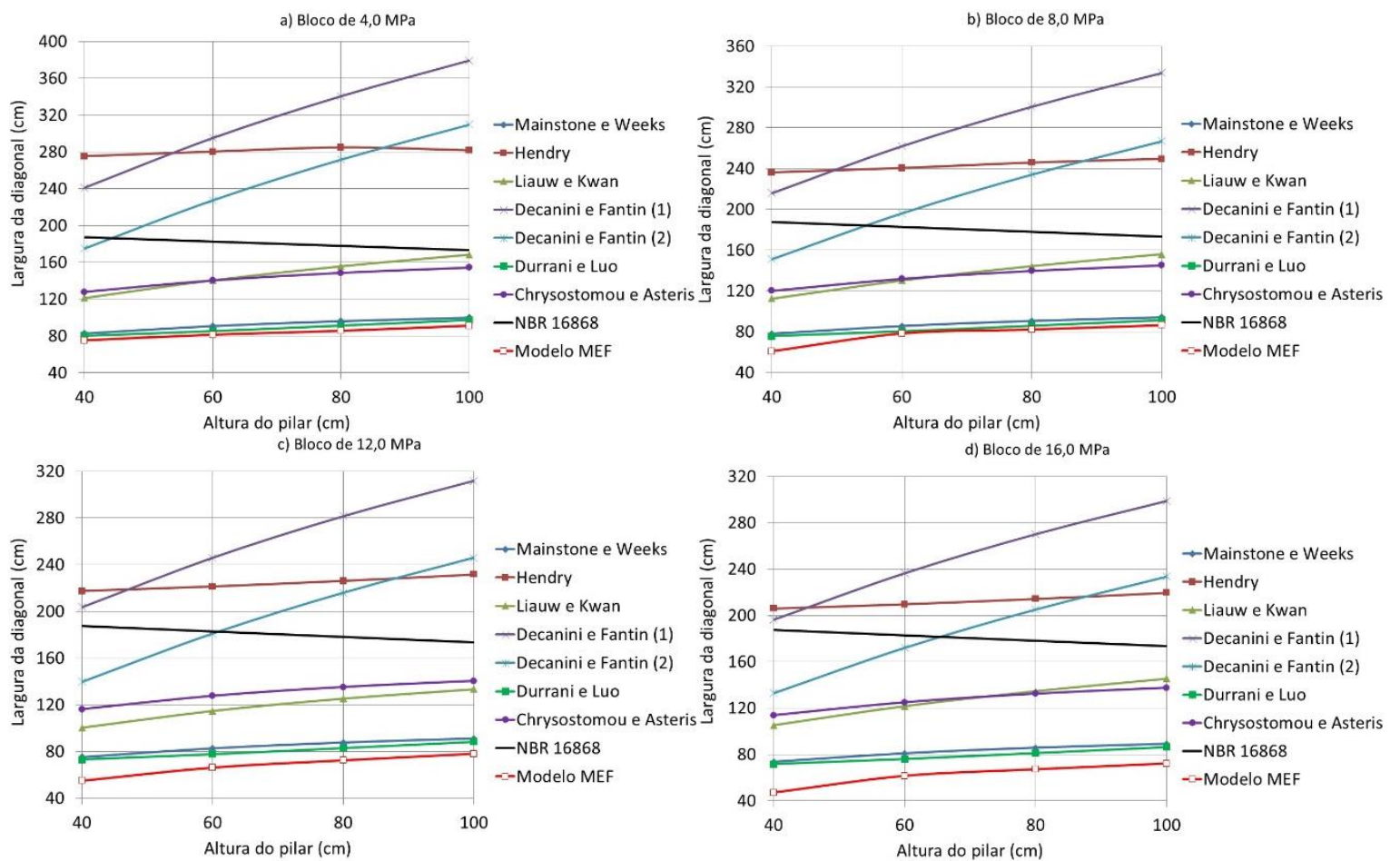

$\rightarrow$ Mainstone e Weeks

-Hendry

$\rightarrow$-Liauw e Kwan

-Decanini e Fantin (1)

-Decanini e Fantin (2)

$\rightarrow$ Durrani e Luo

$\rightarrow$ Chrysostomou e Asteris

-NBR 16868

-Modelo MEF

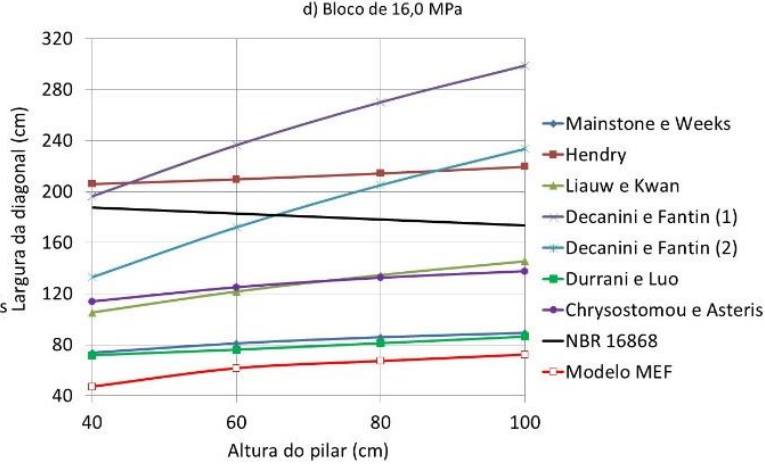

Figura 8: Largura da diagonal equivalente $-\mathrm{L}=7,5 \mathrm{~m}$

Pela análise dos resultados obtidos, percebe-se que o aumento da resistência dos blocos da alvenaria faz com que a largura da diagonal equivalente da modelagem em elementos finitos se aproxime dos valores encontrados aplicando a expressão de MAINSTONE [17], a mais conhecida na literatura e empregada em normas internacionais (considerada também a mais conservadora).

Para os pórticos com viga de vão de 4,5 m a expressão de MAINSTONE [17] apresentou valores mais conservadores do que a simulação em $\mathrm{MEF}$, sendo a largura média obtida com a simulação numérica via MEF 1,35 vezes maior do que a calculada pela expressão analítica. Considerando vigas de 6,0 m, o comportamento se modifica para blocos de resistência à compressão de 12,0 e 16,0 MPa, para os quais a largura obtida pela aplicação da equação de MAINSTONE [17] é maior do que a encontrada pela simulação em MEF. Para os pórticos com esse comprimento de viga, a razão largura modelo MEF/ largura expressão de Mainstone é, em média, 1,01, variando entre 1,16 (razão maior que 1,0 para blocos de 4,0 e 8,0 MPa) e 0,95 (razão menor que 1,0 para blocos de 12,0 e 16,0 MPa). No caso dos pórticos formados por vigas de 7,5 m, a razão largura MEF / largura de Mainstone foi de 0,82.

Com a variação do vão da viga $(\mathrm{L}=4,5 \mathrm{~m} ; 6,0 \mathrm{~m}$ e 7,5 m), nota-se que quanto maior o vão, menos rígida é a estrutura e maiores são os valores de largura da diagonal equivalente calculados em todas as expressões. Assim como no caso da resistência dos blocos, o aumento do vão da viga faz com que a largura da diagonal equivalente calculada com a utilização da modelagem MEF se aproxime dos obtidos com a aplicação da expressão de MAINSTONE [17].

As expressões que forneceram os maiores valores para largura da diagonal, em grande parte dos casos, foram a de DECANINI e FANTIN [20] e HENDRY [18]; e a que forneceu os menores valores, MAINSTONE [17]. Para o vão da viga de 7,5 m, a expressão de DURRANI e LUO [22] apresentou valores bem próximos aos calculados com a utilização da expressão de MAINSTONE [17].

A expressão de DURRANI e LUO [22], para os três comprimentos de vão da viga, apresentou comportamento semelhante quando comparada à simulação via MEF. Para blocos de resistência de 4,0 e 8,0 MPa, os valores de largura da diagonal equivalente foram em média $16 \%$ maiores com a aplicação da expressão em relação aos resultados obtidos via MEF. Já para blocos de resistência 12,0 e 16,0 MPa, esta diferença foi mais expressiva, alcançando valores médios de $43 \%$ de superioridade da expressão analítica sobre a simulação MEF.

A expressão de DECANINI e FANTIN [20] fornece, considerando uma média de todas as simulações realizadas, valores $212 \%$ maiores do que os calculados com a expressão de MAINSTONE [17], evidenciando a grande variação entre as expressões da literatura.

Para todas as expressões, com exceção as das normas CSA S304 [23] e ABNT NBR 16868-1[1], o 
aumento da seção transversal do pilar gerou aumento da largura da diagonal equivalente, o que se pode explicar pela parcela adicional de força horizontal em cada caso, para que se mantenha o mesmo deslocamento horizontal relativo escolhido. Como esperado, o aumento da resistência do bloco (ou o aumento do módulo de elasticidade da alvenaria) gera redução da largura da diagonal equivalente para todas as expressões.

A ABNT NBR 16868-1 [1] forneceu valores de largura da diagonal equivalente superiores aos obtidos via MEF. Para os pórticos formados por vigas de comprimento $4,5 \mathrm{~m}$ as diferenças foram de $65 \%$ (em média) maiores com o cálculo da norma. Quando o vão da viga foi de 6,0 m, os valores da norma se distanciaram mais dos valores em MEF, sendo a largura da diagonal equivalente $116 \%$ maior com a expressão da norma. Para pórticos de 7,5 m, a norma superou em até $229 \%$ o valor encontrado com a simulação computacional via MEF.

\subsection{Análises de deslocamentos no pórtico de múltiplos andares considerando as expressões da litera- tura para o cálculo da largura da diagonal equivalente}

A Tabela 4 apresenta os valores da largura da diagonal equivalente obtidos para cada uma das expressões presentes na literatura. Utilizando o programa FTOOL, para cada valor de largura de diagonal, foram obtidos os deslocamentos horizontais dos pavimentos, os quais estão apresentados no gráfico da Figura 9. Nessa figura também é apresentada a curva de deslocamentos horizontais fornecida com o modelo MEF (ANSYS).

Tabela 4: Largura da diagonal equivalente.

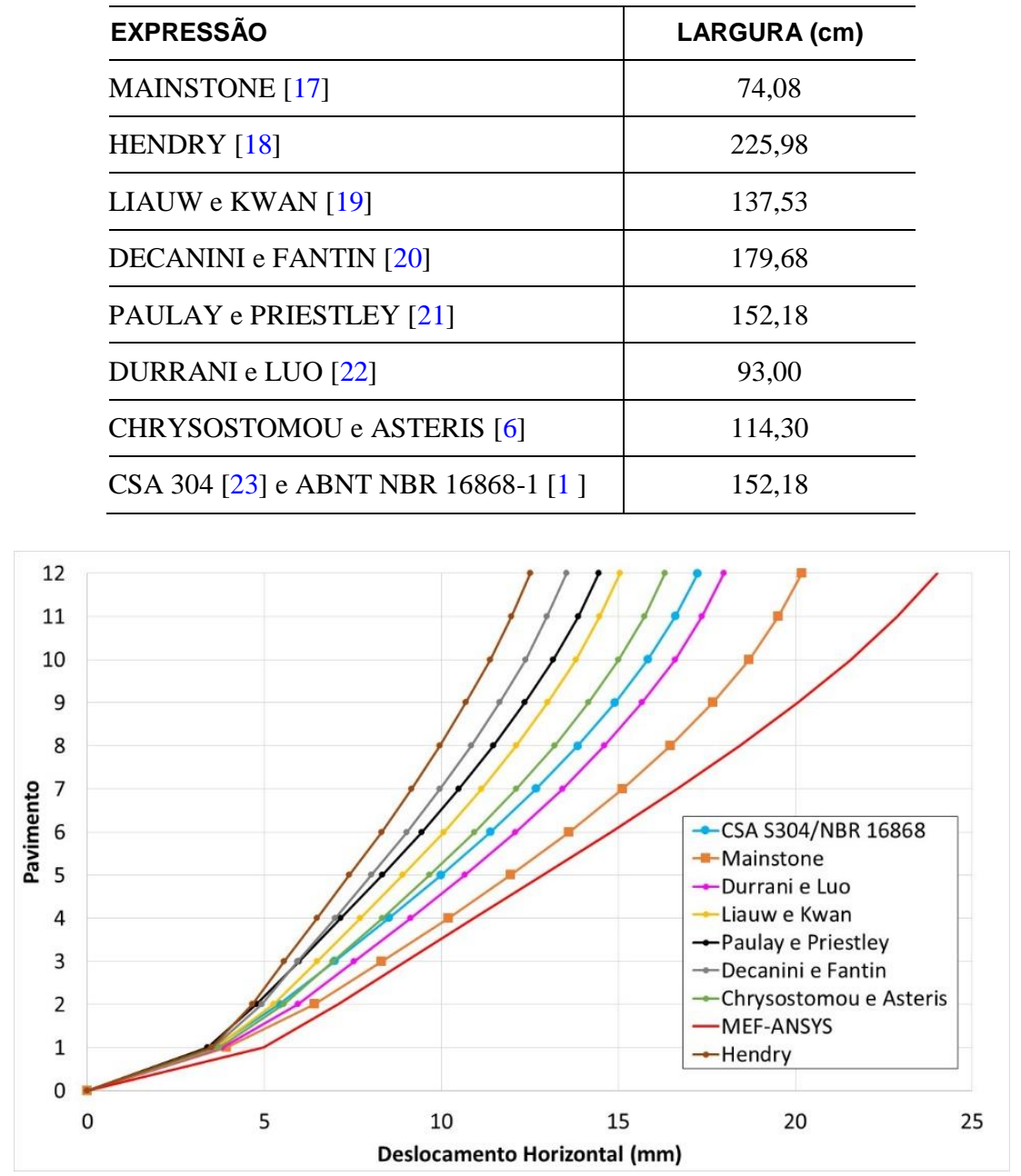

Figura 9: Deslocamento da estrutura devido à ação da força horizontal

Conforme esperado, a grande variação dos valores de largura da diagonal equivalente gerou variações nos deslocamentos encontrados com a aplicação de cada uma das expressões numéricas.

Nota-se também que as expressões que apresentam os maiores valores de largura da diagonal são as 
que fornecem os menores deslocamentos da estrutura, e vice-versa. No entanto, a variação de deslocamento não é proporcional à diferença encontrada no valor da largura da diagonal. Para ilustrar, destaca-se que o maior valor da largura de diagonal equivalente - HENDRY [18] - é 205\% maior do que a menor largura calculada - MAINSTONE [17]; no entanto a média dos deslocamentos dos andares é apenas 55\% maior com a aplicação da largura calculada com MAINSTONE [17].

A expressão que obteve deslocamentos mais próximos aos encontrados com a simulação em MEF foi a de MAINSTONE [17]. As expressões que forneceram os maiores valores para largura da diagonal equivalente foram as de DECANINI e FANTIN [20] e HENDRY [18], sendo estas as que apresentaram também os menores deslocamentos horizontais, consequentemente. A expressão que forneceu os menores valores de largura da diagonal - MAINSTONE [17] - foi a que conduziu a maiores deslocamentos horizontais à estrutura. A expressão recomendada pela ABNT NBR 16868-1 [1] apresentou resultados contrários à segurança em relação às expressões de MAINSTONE [17] e DURRANI e LUO [22], uma vez que conduziu a menores deslocamentos.

\section{CONCLUSÕES}

O trabalho tratou da consideração da alvenaria participante com blocos de concreto em edifícios de concreto armado sob ações horizontais. Foram aplicados dois tipos de modelagem de estruturas: modelos de diagonal equivalente e modelos em elementos finitos, aplicando os programas FTOOL e ANSYS, respectivamente. Nas simulações via MEF, com o auxílio do programa ANSYS, foram empregados elementos finitos bidimensionais de estado plano de tensões com a inclusão do problema de contato alvenaria-pórtico, totalizando 48 modelos numéricos para a comparação com o modelo de diagonal equivalente (MDE). Também foi analisado um pórtico de edifício de 12 andares, com modelagem via MEF e via modelos de diagonal equivalente (MDE), aplicando-se para estes últimos expressões analíticas da literatura para a determinação da rigidez axial das barras diagonais que representam as alvenarias. Foram comparados os deslocamentos horizontais em cada pavimento fornecido por cada expressão (MDE) e pela modelagem MEF.

Para o desenvolvimento das simulações foram aplicadas as recomendações da ABNT NBR 16868-1 [1], no que diz respeito às propriedades mecânicas dos materiais empregados. Quanto às dimensões dos elementos estruturais, buscou-se aplicar dimensões usuais nos projetos desenvolvidos na construção civil. As ações foram calculadas conforme as prescrições das normas brasileiras vigentes.

A partir do desenvolvimento dos modelos foi possível concluir que:

1. Como já constatado por outros autores, há grande variação dos resultados encontrados para a largura da diagonal equivalente aplicando as diversas expressões encontradas na literatura. A expressão que forneceu os maiores valores, DECANINI e FANTIN [20], foi em média, 212\% superior àquela que forneceu os menores valores, MAINSTONE [17]. O aumento da resistência dos blocos da alvenaria faz com que a largura da diagonal equivalente da modelagem em elementos finitos se aproxime dos valores encontrados aplicando a expressão de MAINSTONE [17], a mais conhecida na literatura e empregada em normas internacionais (considerada também a mais conservadora).

2. Com a variação do vão da viga, nota-se que, quanto maior o vão da mesma, menos rígida é a estrutura e maiores são os valores de largura da diagonal equivalente calculados em todas as expressões. Assim como no caso da resistência dos blocos, o aumento do vão da viga faz com que a largura da diagonal equivalente calculada com a utilização da modelagem MEF se aproxime dos obtidos com aplicação da expressão de MAINSTONE [17].

3. Assim como na obtenção da largura da diagonal, nota-se relevante variação nos deslocamentos encontrados com a aplicação de cada uma das expressões numéricas disponíveis na literatura. No entanto, a variação de deslocamento não é proporcional à diferença referente ao valor da largura da diagonal. O maior valor da largura de diagonal equivalente - HENDRY [18] - é 205\% maior do que a menor largura calculada - MAINSTONE [17]; no entanto a média dos deslocamentos dos andares é 55\% maior com a aplicação da largura calculada com MAINSTONE [17].

4. No exemplo de edifício de múltiplos andares, a expressão apresentada pela ABNT NBR 168681[1] conduziu a deslocamentos horizontais menores que os fornecidos pela modelagem de referência (MEF) e menores que os deslocamentos obtidos com o emprego das expressões de MAINSTONE [17] e DURRANI e LUO [22]. 


\section{AGRADECIMENTOS}

Ao Conselho Nacional de Desenvolvimento Científico e Tecnológico (CNPq) pelo apoio financeiro ao segundo autor (Processo: 308720/2018-0)

\section{BIBLIOGRAFIA}

[1] ASSOCIAÇÃO BRASILEIRA DE NORMAS TÉCNICAS (ABNT). NBR 16868-1. Alvenaria estrutural - Parte 1: Projeto. Rio de Janeiro, 2020.

[2] ALVARENGA, R.C.S.S. "Análise teórico-experimental de estruturas compostas de pórticos de aço e preenchidos com alvenaria de concreto celular autoclavado", Tese de D. Sc., Universidade de São Paulo, São Carlos, SP, Brasil, 2002.

[3] POLYAKOV, S.V. "On the interaction between masonry filler walls and enclosing frame when loaded in the plane of the wall", Earthquake Engineering. Earthquake Engineering Research Institute, São Francisco, CA, pp.36-42, 1960.

[4] PARSEKIAN, G.A., HAMID, A.A., DRYSDALE, R.G. Comportamento e dimensionamento de alvenaria estrutural, $2^{\mathrm{a}}$ ed., São Carlos, EdUFSCar, 2013.

[5] CRISAFULLI, F.J.; CARR, A.J. "Proposed macro-model for the analysis of infilled frame structures", Bulletin of the New Zealand Society for Earthquake Engineering, v. 40, n. 2, pp. 69-77, June 2007.

[6] CHRYSOSTOMOU, C.Z., ASTERIS, P.G. "On the in-plane properties and capacities of infilled frames", Engineering Structures, v. 41, pp. 385-402, Aug. 2012.

[7] SANTOS, E.M. "Influência da alvenaria no comportamento estrutural de edifícios altos de concreto armado”, Dissertação de M. Sc., Universidade Católica de Pernambuco, Recife, PE, Brasil, 2007.

[8] MADIA, F.C.A.R. "Estudo de pórticos preenchidos com alvenaria". Dissertação de M. Sc., Universidade Federal de São Carlos, São Carlos, SP, Brasil, 2012.

[9] SILVA, L.R. "Modelagem de pórticos de concreto armado preenchidos com a consideração de aberturas nos painéis de alvenaria”, Dissertação de M. Sc., Universidade Federal de Santa Maria, Santa Maria, RS, Brasil, 2014.

[10] SOUSA, P.V.A. "Efeito dos painéis de vedação nas características dinâmicas de edificações de concreto armado", Dissertação de M. Sc., Universidade Federal do Rio de Janeiro, Rio de Janeiro, RJ, Brasil, 2014.

[11] ALVA, G.M.S., KAMINSKI JR., J., MOHAMAD, G., et al., "Estado limite de serviço de deformações horizontais excessivas com a consideração das alvenarias de preenchimento no modelo estrutural", Revista IBRACON de Estruturas e Materiais, v. 8, n. 3, pp. 390-426, 2015.

[12] MONTANDON, G.A. "Modelos estruturais para a análise de pórticos preenchidos com blocos cerâmicos em edifícios de concreto armado", Dissertação de M. Sc., Universidade Federal de Uberlândia, Uberlândia, MG, 2018.

[13] MEDEIROS, W.A. "Pórticos em concreto pré-moldado preenchidos com alvenaria participante", Dissertação de M. Sc., Universidade Federal de São Carlos, São Carlos, SP, Brasil, 2018.

[14] GRANDI, A.B.C. "Avaliação experimental por meio de ensaios cíclicos de pórtico de aço preenchido com alvenaria participante”, Dissertação de M. Sc., Universidade Federal de Viçosa, Viçosa, MG, Brasil, 2018.

[15] ALVA, G.M.S., MONTANDON, G.A. "Modelos estruturais para a análise de pórticos preenchidos com alvenaria em edifícios de concreto armado", Revista IBRACON de Estruturas e Materiais, v.12, n.5, p.1058$1085,2019$.

[16] QUEIROZ, L.F. "Alvenarias participantes: consideração e efeitos em edifícios de concreto sob ações horizontais”, Dissertação de M. Sc., Universidade Federal de Uberlândia, Uberlândia, MG, 2020.

[17] MAINSTONE, R.J. "Supplementary note on the stiffness and strengths of infilled frames", Building Research Station, Garston, UK, 1974.

[18] HENDRY, A.W. Structural Brickwork, London, MacMillan, 1981.

[19] LIAUW, T.C., KWAN, K.H. "Nonlinear behavior of non-integral infilled frames". Computers and Structures, v. 18, n. 3, pp. 551-560, 1984. 
[20] DECANINI, L.D., FANTIN, G.E. "Modelos simplificados de la mampostería incluida en porticos. Caracteristicas de rigidez y resistencia lateral en estado limite", In: Jornadas Argentinas de Ingeniería Estructural, v. 2, pp. 817-836, Buenos Aires, 1986.

[21] PAUlAY, T., PRIESTLEY, M.J.N. "Seismic design of reinforced concrete and masonry buildings", New York, Wiley, 1992.

[22] DURRANI, A.J., LUO, Y.H. "Seismic retrofit of flat-slab buildings with masonry infills", Proceedings from the NCEER Workshop on Seismic Response of Masonry Infills, National Center for Engineering Earthquake, Buffalo, N.Y., 1994.

[23] CANADIAN STARDARDS ASSOCIATION. S304 - Design of masonry structures. CSA. Ontario. 2014.

[24] ASSOCIAÇÃO BRASILEIRA DE NORMAS TÉCNICAS (ABNT). NBR 6118. Projeto de estruturas de concreto - Procedimento. Rio de Janeiro, 2014.

[25] ALVA, G.M.S., KAMINSKI JR., J.; RIGÃO, A.O., et al., "Consideração das alvenarias participantes na rigidez lateral de edifícios de concreto armado”, In: 61 Congresso Brasileiro do Concreto, pp.1-16, Fortaleza, 2019.

\section{ORCID}

Luiz Flávio de Queiroz

Gerson Moacyr Sisniegas Alva https://orcid.org/0000-0002-7490-0461

https://orcid.org/0000-0002-2528-5757 